\title{
Research on MIL Education Status Quo and Promotion Strategies of College Teachers
}

\author{
Si-Si CHEN, Jian-Qiang SUN, Li WANG* \\ Jiangxi University of Traditional Chinese Medicine \\ Nanchang, Jiangxi \\ Corresponding Author: Li Wang (Email:wangli0550@163.com)
}

\begin{abstract}
Under the "Internet +"new normal view, the MIL (media and information literacy) education has become the trend of the integration of Internet, pedagogy, and communication. At the same time, taking MIL education of college teachers as a starting point will be conducive to the advancement of higher education and the construction of network power. This paper clarifies the conceptual connotation of college teachers' MIL, analyzes the research status and existing problems of MIL and college teachers' MIL education from three aspects of government, universities and teachers respectively, and put forward the promotion strategies of college teachers' MIL education.
\end{abstract}

Keywords-Media and information literacy; College teacher; MIL education; Promotion strategy

\section{INTRODUCTION}

In April 2018, Chairman Xi Jinping emphasized at the National Conference on Cyber Security and Informatization that "Sharply seize the historic opportunity of informationbased development, independent innovation promotes the construction of an internet power, continuously promotes innovation in theory and practice, and strengthens Internet positive propaganda and ideal faith education" [1]. In the key points of the Ministry of Education's work in 2018, it was emphasized that in-depth advancement of education informatization, the launch of the Education Informatization 2.0 Action Plan, the implementation of the in-depth fusion of information technology and education, and the advancement of college classroom revolution [2]. The development of network information dissemination and sharing and media technology has put forward requirements for the conformity to the development of the times and the reform and innovation of higher education. The promotion of college teachers' MIL education is an inevitable requirement for the deep integration of Internet development and education, and it is a powerful intellectual carrier for China's independent innovation to promote the building of an internet power.

\section{THE CONCEPT AND CONNOTATION OF MIL}

MIL is media and information literacy, came from the concept of "media = information" of McLuhan, a Canadian communication theorist in the 1960s, believes that the media is dependent on information but not isolated, therefore media and Information is inseparable [3]. In 2013, UNESCO issued the Media and Information Literacy Policy and Strategy Guidelines, putted forward the definition of MIL first time, the fusion concept of Information literacy and media literacy by means of Information Communication Technology (ICT) to express and access to freedom information rights. Indicate the MIL concept as: A combination of capabilities that allows citizens to use a range of tools, to get, retrieve, understand, evaluate, use, create, and share all format information in a critical, ethical and effective way, and participate in personalization, specialization, and socialization activities [4].

In different fields, occupations, and industries, MIL focuses on different aspects in its conceptual connotation. Based on the nature of work and industry characteristics of college teachers, this paper considers that the concept of college teachers' MIL is: College teachers use media to select, use, recognize, judge, and disseminate knowledge resources and information, and can be effectively applied to the comprehensive quality of teaching, academic, and subject development. The core connotation of college teachers' MIL should be two aspects: First, college teachers' ability to use the media and access to information resources; Second, they can use what they have learned to develop their abilities to use in education and teaching. 


\section{Status QuO OF COLlEGE TEACHERS' MIL EduCATION}

This study from three aspects: From the perspective of government, universities and college teachers, the status quo and inadequacies of college teachers' MIL education are analyzed.

\section{A. Absence of Government Education Policy}

The lack of relevant policy guidelines and strategies at the government level has resulted in the incomplete education content of college MIL education. Internationally, UNESCO has played an important role in the global education of MIL, and has repeatedly published resolutions, declarations and readings, which has contributed to the globalization of MIL education [5]. The start of MIL research in our country is still relatively shallow and has not yet formed a complete system of disciplines. MIL education for college teachers is mostly based on information technology education, literature retrieval education and information knowledge training. Usually it is only conducted in the form of short-term training courses or conferences, that does not fully support MIL education for college teachers from the level of education policy. This lack of systematic and continuous forms of learning has led to problems in the use of information technology for teaching [6].

\section{B. Insufficient Attention from Universities}

The general degree of attention in universities is not high, resulting in college teachers' MIL levels are low. At present, most colleges and universities in China do not fully develop MIL education and use the experience of learning related fields for reference, but they still do not have an innovative training model. In recent years, the MOOC curriculum construction popular in universities, the opening of elite resources online courses, and micro-classrooms have increased the use of teachers' educational technology and educational information to a certain degree, but they are also prone to cause tool rational thinking and cannot fully reflect the Essential Connotation of University Teachers' MIL.

\section{Insufficient Personal Learning of College Teachers}

The lack of individual cognitive ability and learning ability of teachers leads to insufficient self-education. The core of education - the theory of man's all-round development, considers self-learning and life-long learning to be an important part of all stages of life. Teachers' teaching should keep pace with the times and keep the initial heart of learning to learn. Most teachers understand the concept and connotation of MIL one-sidedly, with the renewal of information technology and knowledge, they do not pay attention and study in a timely manner and cannot apply the knowledge learned to teaching and practice [7].

\section{KEy CONTENTS AND PROMOTION STRATEGIES OF COLLEGE TEACHERS' MIL EDUCATION}

\section{A. Key Contents of College Teachers' MIL Education}

Generally with the gradual deepening of the economic and information society, MIL education is also gradually developing, it mainly refers to the development of MIL education courses, the promotion of ICT integration and education, the provision of MIL education training for teachers, and the periodic organization MIL training activities by library. Therefore, China's MIL education in universities is to promote the level of MIL education and more people access to information and knowledge. This study accounts that the key content of MIL education in our universities is cognition and moral value judgment ability of media information, network media selection and information utilization ability, and ICT expression ability in education and teaching.

1) Media Information Cognition and Moral Value Evaluation Ability

For the mass media, it has political, economic, and public attributes, the source of media profit is the basis for the existence of media, the profit sources of media such as websites, television, newspapers, and broadcasts are different, which means that their respective attributes are different [10]. In the teaching situation the MIL level of college teachers influences whether they can correctly implement the educational concept of" for whom to trains people, what kind of people to train, how to cultivate people". For college teachers, the path to human-oriented education is the cognition and moral judgment, critique information and takes its essence to its dross.

\section{2) Network Media Selection and Information Utilization} Capability

The 41st Statistical Report on Internet Development in China pointed out that the proportion of computer access to the Internet in schools has increased from $16.5 \%$ to $19.1 \%$ [8]. The Development of the National Education Industry in 2016 pointed out that there were 27.0 teaching computers per 100 students in ordinary colleges and universities in China, and the average online courses for ordinary universities were 169.9[9]. It can be seen that the development and progress of educational technology has determined that college teachers are no longer confined to paper-based communication tools in teaching and scientific research. The use and popularization of the Internet has penetrated into all aspects of education and teaching. Relying solely on traditional media can no longer satisfy students the need for training that focus must be to strengthen teachers' online media choice and information utilization capabilities. 


\section{3) ICT's expressive ability in education}

The 10 Years of Education Informatization Development Plan (2011-2020) clearly pointed out that we must speed up the construction of the "three links and two platforms" and strive to promote the integration of teaching and information technology [11]. Learning is just for use, the purpose of the MIL education for teachers is to play a role in education, by using the uniqueness of the teacher, that is as a communicator of knowledge and information culture, expected to reach a deeper and broader educational goal. An important embodiment of college teachers' MIL is the knowledge and education resources that are disseminated through specific carriers, use information media to interact and spread, and improve the ability of knowledge communication and acceptance of new things.

\section{B. Promotion Strategy of College Teachers' MIL Education}

\section{1) Building a Smart Campus Environment}

The government should support the construction of a smart campus environment in colleges and universities, through the use of information technology, it can effectively integrate and optimize various types of information culture resources inside and outside the campus, realize effective allocation and utilization of knowledge and cultural resources, and provide digital teaching, learning, scientific research and management for the campus. A good information environment can stimulate the enthusiasm of teachers to use modern information technology to carry out teaching and research activities. First, in order to adapt to the working environment, teachers will actively seek to improve their own MIL channels and means; Second, the environment itself provides teachers with space for practice in teaching and research; Third, the construction of a smart campus environment enriches the university's campus cultural construction.

\section{2) Combining MIL Education with Teacher} Professionalism

College teachers are usually professional and technical personnel and have relatively stable professional fields. MIL education cannot be "one size fits all". Combining MIL education with teacher professionalism, designing training topics and content, stimulating the enthusiasm and initiative of teacher participation, cultivating autonomous learning and research capabilities, and making teachers easy to generate interest and effectiveness in their familiar fields, then derive more innovative ideas and innovative practices. It will help teachers to fully utilize information technology in their learning and improvement to further explore specialized fields, and combine professional expertise with the use of media to effectively disseminate and utilize knowledge resources.

\section{3) Encouraging teachers to participate in learning}

The improvement of literacy is focused on fostering habits. Mature-conditioned schools can create an environment for teachers to participate in the training and improvement of the real situation of media education. For example, they can work with the media and third parties to enable teachers to enter newspapers, radio stations, television stations, news media groups, and online information companies, to visit, study, practice, and even with more mature universities secondment, appointment, job placement, poverty alleviation, entrepreneurship and other personnel training mechanism, direct participation in the media work, will receive better results. Only by truly participating in the learning of media and information-related knowledge can we develop a good MIL and it is useful to do what we learn.

\section{4) Setting up an on-campus MIL sharing platform}

MIL education is not a simple short-term passive training for college teachers, but a systematic project of mutual exchange and long-term infiltration between education subject and object, education object. Teachers are both the object of education and the subject of learning. As universities, in order to facilitate the exchange and sharing of information among teachers, it is necessary to establish a shared platform that includes information knowledge, media literacy, and industry hotspot frontier knowledge [12]. For example, the establishment of a MIL education website, a MIL education sharing micro-platform, a multimedia distribution platform, etc. facilitates the sharing of teacher resources within the school and facilitates timely exchange and discussion, promotes mutual promotion, self-growth, and makes MIL an important content of lifelong education.

\section{CONCLUSION}

Education is a process of cultivating thinking and improving the comprehensive quality. Through the education of college teachers, their cognitive status and behavior can be changed, and more people and even the entire society can be influenced through teaching and educating people. This paper analyzes the deficiencies of college teachers' MIL education at the government, universities and teachers, and puts forward the key content and promotion strategies of college teachers' MIL education. However, university teachers' MIL education also needs collaborative work, active innovation, and key advancement at all levels of society. MIL education will be built into a systematic education project, starting from college teachers' MIL education, then will gradually move toward more fields and people. 


\section{ACKNOWLEDGEMENTS}

Fund Project: China High Education Association Public Relations Committee Project: Research on the University Teacher's Media and Information Literacy (MIL) under the New Normal of "Internet + "Education

\section{REFERENCES}

[1] Xinhuanet. $\mathrm{Xi}$ Jin ping: Independent Innovation Promotes the Construction of CyberPowers[EB/OL].http://www.xinhuanet.com/politics/201804/21/c_1122719810.htm,2018-04-21. (In Chinese)

[2] Ministry of Education of the People's Republic of China. Notice of the Ministry of Education on Printing and Distributing the Main Points of the Ministry of Education in 2018.[EB/OL].http://www.moe.gov.cn/srcsite/A02/s7049/201802/t2018 0206_326950.html, 2018-02-01. (In Chinese)

[3] Marshall McLuhan. Understanding the media - on human extension [D]. He Daokuan translation. Beijing: Commercial Press, 2000:33. (In Chinese)

[4] Cheng Mengmeng, Xia Wenjing, Wang Jiazhou, et al. Interpretation of the Global Media and Information Literacy Assessment Framework (UNESCO) and Its Implications [J]. Journal of Distance Education, 2015(1):21-29. (In Chinese)

[5] Lu Feng. Localization of Media Literacy Education [D]. Nanjing Normal University, 2011. (In Chinese)

[6] Liang Haixia. Research on the Information Literacy of Young Teachers in Colleges and Universities in the Age of 'Internet+' [J]. Asia-Pacific Education, 2015(34):195-195. (In Chinese)

[7] Lin Jiangmei. Research on the Strategy of Promoting Information Literacy of Teacher Education in the Era of Big Data [J]. Asia-Pacific Education, 2015(3):106-107. (In Chinese)

[8] National Internet Information Office of the People's Republic of China. The 41st Statistical Report on Internet Development in China. [EB/OL]. http://www.cac.gov.cn/2018-01/31/c_1122347026.htm. (In Chinese)

[9] The Ministry of Education of the People's Republic of China. "China's Education Overview - National Education Development in 2016".[EB/OL].www.moe.gov.cn/jyb_sjzl/s5990/201711/t20171110_31 8862.html. (In Chinese)

[10] Li Yuchun. Investigation on Status Quo of Teacher Literacy in Electronic Science and Technology University and Countermeasures [D]. University of Electronic Science and Technology of China, 2013. (In Chinese)

[11] Ministry of Education of the People's Republic of China. Notice of the Ministry of Education on Printing and Distributing the"10-year Development Plan for Educational Informationization (20112020)"[EB/OL].http://old.moe.gov.cn//publicfiles/business/htmlfiles/mo e/s3342/201203/133322.html. (In Chinese)

[12] Li Xin. Status quo and countermeasures of college teachers' media literacy $[\mathrm{J}]$. News and World Forum, 2nd half of the issue, 2010(5):1415. (In Chinese) 